\title{
Implementasi Waterfall Model Pada Sistem Informasi Penyewaan Tanah Makam pada TPU Perwira
}

\author{
Hendri $^{1}$, Dony Oscar², Rachman Komarudin ${ }^{3}$ \\ ${ }^{1,3}$ STMIK Nusa Mandiri, \\ ${ }^{2}$ Universitas Bina Sarana Informatika

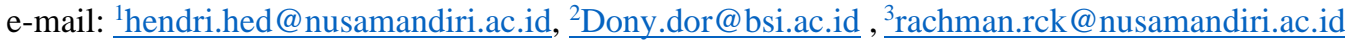

\begin{tabular}{ccc} 
Diterima & Direvisi & Disetujui \\
$27-10-2020$ & $09-11-2020$ & $15-12-2020$ \\
\hline
\end{tabular}

\begin{abstract}
Abstrak - Dengan kemudahan dalam pengaksesan terhadap data atau informasi yang tersedia dapat berlangsung dengan cepat, efisien serta akurat. Hal ini membuat teknologi Informasi menjadi salah satu bidang yang sedang berkembang dengan sangat cepat. Dalam proses penyewaan tanah makam pada TPU Perwira masih menggunakan cara manual karena diharuskan bertatap muka antara ahli waris dengan staff TPU. Akibatnya, proses penyewaan tanah makam kurang efektif dan efesien, karena ahli waris tidak mengetahui kondisi lahan dan keberadaan lahan yang kosong sehingga keadaan makam belum pasti kosong atau sudah dimiliki ataupun dipesan oleh orang lain. Tujuan dari penelitian ini adalah pembangunan sistem informasi pemesanan pemakaman umum di TPU Perwira yang berbasis web. Sehingga pendataan makam pada TPU Perwira dapat terdata dengan baik dan terorganisir serta membuat tata lahan pemakaman terkondisikan dengan lebih baik. Metode penelitian menggunakan Metode waterfall dengan beberapa tahapan yang runtut yaitu : analisis kebutuhan, desain sistem, coding \& testing, penerapan program, dan pemeliharaan (Morris, 1942). Dengan adanya sistem penyewaan tanah makam berbasis web ini, diharapkan tidak hanya membantu dan mempermudah ahli waris dalam melakukan penyewaan tanah makam tetapi juga dapat membantu staff TPU perwira dalam pengelolaan area pemakaman yang ada dengan tingkat akurasi data yang lebih baik.
\end{abstract}

Kata Kunci: Sistem Informasi, Sistem Penyewaan Tanah Makam, Waterfall.

\begin{abstract}
Abstrak - With easy access to available data or information, it can take place quickly, efficiently and accurately. This makes Information technology one of the fastest growing fields. In the process of renting a grave land at the perwira cemetery, it still uses manual methods because it requires face-to-face contact between the heirs and the TPU staff. As a result, the process of renting grave land is less effective and efficient, because the heirs do not know the condition of the land and the existence of empty land so that the condition of the tomb is not certain that it is empty or has been owned or ordered by someone else. The purpose of this research is the development of a web-based public cemetery ordering information system at the TPU Perwira. So that the data collection of the graves at the Perwira Cemetery can be well recorded and organized and make the cemetery layout better conditioned. The research method uses the waterfall method with several coherent stages, namely: needs analysis, system design, coding \& testing, program implementation, and maintenance (Morris, 1942). With this web-based burial land rental system, it is hoped that it will not only help and make it easier for the heirs to lease grave land but can also help TPU perwira staff in managing the existing burial area with a better data accuracy.
\end{abstract}

Keywords: Information System, The System of Leasing Land Tomb, Waterfall.

\section{PENDAHULUAN}

Penelitian terdahulu yang penulis gunakan pada penelitian ini adalah penelitian dengan judul "Rancang bangun sistem informasi pengelolaan makam berbasis web pada pemakaman wakaf bungur kebayoran lama" (Trianto \& Setiawan, 2020) pada penelitian ini dibahas tentang pembangunan sistem pengelolaan tanah pemakaman berbasis web, dengan tujuan untuk membantu ahli waris dalam mengetahui ketersediaan lahan untuk makam yang akan di sewa. Pada penelitian ini juga dibahas proses pembayaran sewa lahan pemakaman yang ada pada pemakaman wakaf bungur kebayoran lama. Namun pada penelitian ini tidak ada fasilitas untuk surat peryataan keaslian berkas yang dibutuhkan dalam proses pendaftaran sewa lahan pemakaman.

"Sistem Informasi telah menjadi suatu kebutuhan yang mendesak di berbagai bidang kehidupan termasuk bidang bisnis. Sistem informasi adalah data yang dikumpulkan, diklasifikasikan dan diolah 
sedemikian rupa sehingga menjadi sebuah informasi entitas terkait tunggal dan mendukung satu sama lain sehingga menjadi informasi berharga bagi mereka yang menerimanya" (Sukrianto \& Agustina, 2018). Sebagian besar institusi yang bergerak dalam bidang bisnis telah menjadikan sistem informasi sebagai bagian yang penting dalam pengembangan bisnisnya. Hal lain yang dapat dijadikan sebagai contoh dalam perkembangan teknologi informasi adalah terhubung nya data ke dalam jaringan internet yang memungkinkan bagi semua umat manusia untuk menggunakan data tersebut secara bersamasama. Implementasi suatu sistem yang dapat merekam semua proses pencatatan data baik data pelanggan, data pemesanan, data pembayaran yang bersifat terkomputerisasi merupakan Salah satu contoh aplikasi teknologi informasi di bidang jasa. Pemanfaatan teknologi informasi memiliki cangkupan yang sangat luas,. Salah satunya adalah dalam bidang pemakaman. Pemakaman sering menjadi isu "terbelakang" dalam kehidupan ini. Padahal jika melihat "kodrat" kita sebagai manusia kita semua akan mengalami apa yang dinamakan dengan kematian. Semakin meningkatnya jumlah penduduk, dapat mengakibatkan adanya persoalan terkait kebutuhan lahan bagi penduduk yang mengalami kematian. Karena semakin lama lahan pemakaman akan semakin padat jika tidak disertai dengan adanya penyedian lahan tambahan atau melakukan perluasan lahan makam. Saat ini, masih banyak tempat pemakaman yang memiliki keterbatasan dalam hal penyediaan lahan makam. Namun keterbatasan lahan makam ini dapat diatasi dengan sistem makam tumpuk atau tumpangsari, yaitu penumpukan jenazah dalam satu kuburan.

Hal tersebut menjadi permasalahan yang harus dipecahkan dan menjadi masalah yang cukup serius dan perlu penanganan yang serius pula. Salah satu yang menjadi solusi pemecahan permasalahan tersebut adalah penggunaan teknologi informasi untuk mendata keseluruhan angka kematian yang terjadi dan juga mendata ketersediaan lokasi yang ada untuk memakamkannya. Dengan begitu pihak yang berwenang dalam hal ini pemerintah dapat memantau setiap permasalahan yang ada dan dapat memberikan solusi yang dapat disebarluaskan dengan mudah dengan memanfaatkan teknologi informasi yang telah dibangun.

Sebagai salah satu contohnya adalah Tempat Pemakaman Umum Perwira. Tempat Pemakaman Umum Perwira adalah salah satu tempat yang menyediakan lokasi untuk pemakaman

TPU Perwira merupakan salah satu TPU yang memiliki banyak kekurangan. Seperti pada lahan makan yang masih sangat kurang sehingga beberapa makan harus ditumpuk menjadi tingkat tiga. Lalu pada proses pendaftaran makam, para pendaftar yang akan menggunakan lahan makam di TPU Perwira tidak mengetahui kondisi lahan dan keberadaan lahan yang kosong sehingga keadaan makam belum pasti kosong atau sudah dimiliki atapun dipesan oleh orang lain. Terakhir, tidak ada data tempat jenazah atau makan sehingga hal ini sangat menyulitkan untuk mengetahui keberadaan makan tersebut. Hal tersebut menjadi permasalahan tersendiri, seharusnya sudah menerapkan suatu sistem yang mamanfaatkan perkembangan teknologi informasi untuk membantu pemaksimalan proses bisnis yang berlangsung di suatu organisasi.

Berdasarkan pada uraian diatas, diusulkan adanya pembangunan sistem informasi pemesanan pemakaman umum di TPU Perwira yang berbasis web. Sehingga tujuan dari penelitian ini adalah pembangunan sistem informasi pemesanan pemakaman umum di TPU Perwira yang berbasis web. Agar pendataan makam pada TPU Perwira dapat terdata dengan baik dan terorganisir serta membuat tata lahan pemakaman terkondisikan dengan rapih.

\section{KAJIAN LITERATUR}

\section{Pembelajaran Berbasis Web}

Dengan pertumbuhan internet yang pesat, web telah menjadi suatu media belajar dan mengajar jarak jauh yang penuh daya, interaktif, dinamik, ekonomis dan demokratis. Web menyediakan suatu kesempatan mengembangkan pembelajaran dan pelatihan yang sesuai tuntutan dan berorientasi pada yang belajar (learning centered). Web juga merupakan representasi suatu paradigma baru mengenai pembelajaran terutama bagaimana pembelajaran diorganisasikan dan disajikan (Rusman, 2013).

\section{Sistem Informasi}

Sistem didefinisikan sebagai sekumpulan prosedur yang saling berkaitan dan saling terhubung untuk melakukan suatu tugas bersama-sama. Secara garis besar sistem, sebuah sistem informasi terdiri atas tiga komponen utama. Ketiga komponen tersebut mencakup software, hardware, dan brainware. (Pratama, I., \& Eka, 2014). Sistem Informasi merupakan kumpulan dari perangkat keras dan perangkat lunak serta perangkat manusia yang akan mengolah data menggunakan perangkat keras dan perangkat lunak tersebut, selain itu data juga memegang peranan yang penting dalam sistem informasi, data yang akan dimasukkan ke dalam sebuah sistem informasi dapat berupa formulirformulir, prosedur-prosedur, dan bentuk data lainnya (Krispriana et al., 2018).

\section{Website}

Menurut (Ardhana, 2012) dalam (Hirmawan et al., 2016) website atau situs web adalah sejumlah halaman web yang memiliki topik saling terkait, 
terkadang disertai pula dengan berkas-be rkas gambar, video, atau berkas lainnya. Situs web adalah kumpulan dari halaman web yang sudah dipublikasikan di jaringan internet dan memiliki domain/URL (Unifed Resource Locator) yang dapat diakses semua pengguna internet dengan cara mengetikan alamatnya.

\section{Basis Data}

Pada penelitian yang dilakukan oleh haryadi dijelaskan "Sistem basis data merupakan sistem ter komputerisasi yang arah utamanya untuk memelihara data yang telah diolah atau informasi kemudian membuat informasi tersebut tersedia saat dibutuhkan" (Haryadi \& Melian, n.d.). Sedangkan pada penelitian yang di lakukan oleh Yosefh salli padang disebutkan bahwa "Basis data adalah kumpulan data yang saling berhubungan antara data yang satu dengan yang lainnya, Data ialah fakta mengenai objek orang dan lainnya" (Padang et al., 2018).

\section{Model Pengembangan Perangkat Lunak}

Metode waterfall adalah suatu proses pengembangan perangkat lunak yang sistemnya terurut, di mana kemajuan dipandang sebagai terus mengalir ke bawah (seperti air terjun) melewati fase-fase perencanaan, pemodelan, implementasi (konstruksi), dan pengujian. Dalam pengembangannya metode waterfall mempunyai beberapa tahapan yang runtut : requirement (analisis kebutuhan), desain sistem (system design), coding \& testing, penerapan program, dan pemeliharaan (Morris, 1942).

\section{METODE PENELITIAN}

Metode yang digunakan pada pengembangan perangkat lunak ini menggunakan model "waterfall". Menurut (Sukamto, A. R., \& Shalahuddin, 2014) "Model SDLC air terjun (waterfall) sering juga disebut model sekuensial linier atau alur hidup klasik (classic life cycle)". Model air terjun menyediakan pendekatan alur hidup perangkat lunak secara sekuensial atau terurut dimulai dari analisi, desain, pengkodean, pengujian dan tahap pendukung (support).

a. Analisa

Kebutuhan Perangkat Lunak Proses pengumpulan kebutuhan dilakukan secara intensif untuk menspesifikasikan kebutuhan perangkat lunak agar dapat dipahami perangkat lunak seperti apa yang dibutuhkan oleh user. Tahapan ini merupakan proses dimana penulis menentukkan klasifikasi data yang akan membantu dan mendukung dalam perancangan basis data untuk mempermudah dan memperjelas dalam pengaksesan website yang akan dibuat. Peneliti mengumpulkan data mulai dari harga sewa lahan, tipe blok, dan alur dari proses penyewaan lahan di TPU Perwira, kemudian menganalisa data tersebut agar sesuai dengan yang dibutuhkan.

b. Desain

Desain perangkat lunak adalah proses multi rangkap yang fokus pada desain pembuatan program perangkat lunak termasuk struktur data, arsitektur perangkat lunak, representasi antarmuka, dan prosedur pengodean. Tahap ini mentranslasi kebutuhan perangkat lunak dari tahap analisa kebutuhan ke representasi desain agar dapat diimplementasikan menjadi program pada tahap selanjutnya. Di tahap ini, peneliti menentukan dan membuat desain sistem dan aliran proses dari sistem yang akan dirancang.

c. Pembuatan Kode Program

Untuk tahap ini, penulis mulai melakukan pengkodean menggunakan bahasa pemrograman yang telah ditentukan untuk menciptakan desain sistem dan aliran proses yang telah dirancang sebelumnya.

\section{d. Pengujian}

Pengujian perangkat lunak pada penelitian ini fokus pada perangkat lunak dari segi logic dan fungsional serta memastikan bahwa semua bagian sudah di uji. Hal ini dilakukan untuk mengurangi tingkat kesalahan (error) dan memastikan bahwa output yang dihasilkan sesuai dengan yang diharapkan. Pengujian perangkat lunak memiliki peranan penting dalam suatu sistem informasi, dengan pengujian ini dapat diketahui galat atau error yang akan muncul pada perangkat lunak.Dengan pengujian perangkat lunak diharapkan dapat meminimalisir kesalahan dan cacat pada sebuah software dan sebagai pengukuran kualitas dari software tersebut (Debiyanti et al., 2020) .Menurut (Sukamto, A. R., \& Shalahuddin, 2014) "Black Box Testing (pengujian kotak hitam) dengan menguji perangkat lunak dari segi spesifikasi fungsional tanpa pengujian desain dan kode program".

\section{e. Pendukung (support) atau Pemeliharaan (maintenance)}

Tidak menutup kemungkinan sebuah perangkat lunak mengalami perubahan ketika sudah di kirimkan ke user. Perubahan bisa terjadi karena adanya kesalahan yang muncul dan tidak terdeteksi saat pengujian atau perangkat lunak harus beradaptasi dengan lingkungan baru.

\section{HASIL DAN PEMBAHASAN}

a. Prosedur Sistem Berjalan

Prosedur sistem berjalan ini bertujuan untuk menguraikan proses secara sistematis tentang aktivitas penyewaan lahan makam yang terjadi di TPU Perwira. Prosedur sistem berjalan yang masih diterapkan oleh TPU Perwira Bekasi masih belum terkomputerisasi. Di mana dalam proses penyewaan lahan makamnya dilakukan dengan cara ahli waris datang ke TPU Perwira dengan membawa berkas persyaratan yang terdiri dari, KTP almarhum dengan surat keterangan kematian. Lalu, ahli waris mengisi 
formulir yang telah disiapkan oleh pihak TPU Perwira berupa Surat Daftar Perizinan Penggunaan Tanah Makam, Surat Pernyataan dan Surat Pernyataan Keaslian dan Kebenaran Berkas. Hal ini menyebabkan ketidak efisienan dalam proses melakukan pemesanan lahan makam karena akan memakan banyak waktu serta membuat sulit keluarga duka yang sedang tidak berada di lokasi dekat pemakaman. Oleh karena itu sistem itu perlu digantikan dengan sistem yang sudah terkomputerisasi agar dapat memudahkan dalam proses pemesanan lahan makam.

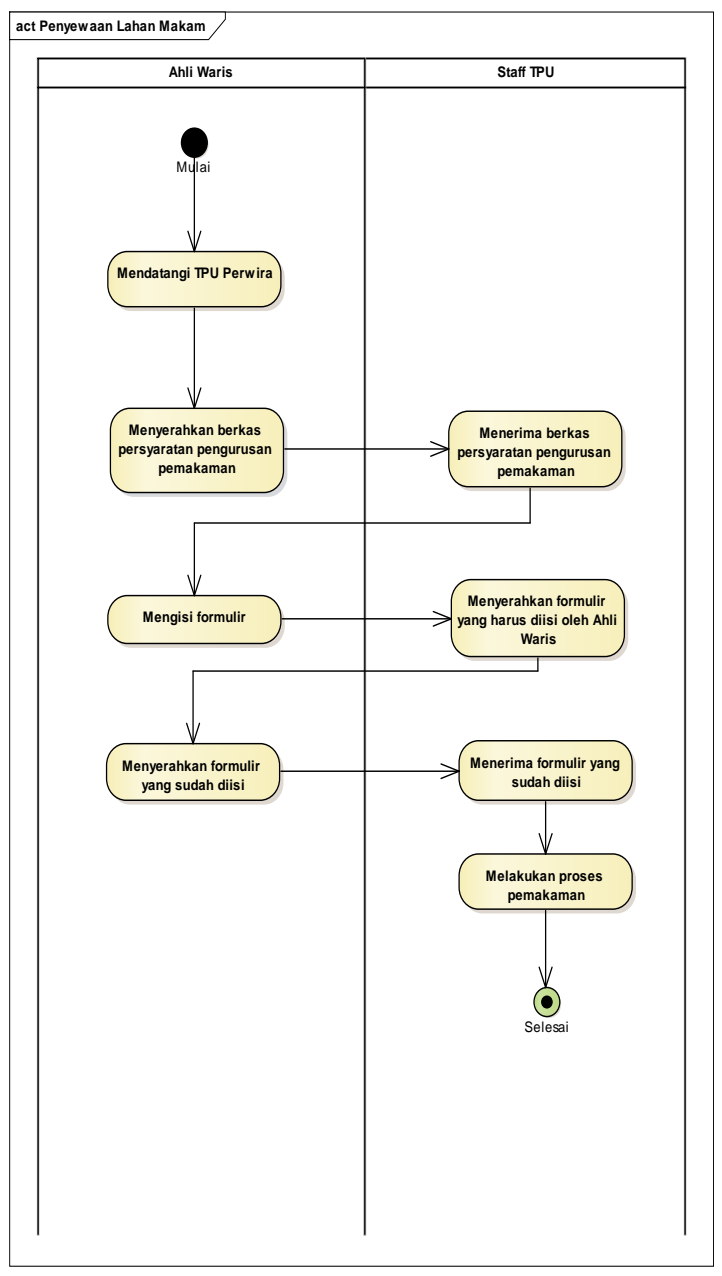

Sumber : penelitian 2020

\section{Gambar 1. Prosedur Penyewaan Lahan Makam}

b. Use Case Diagram

(Sukamto, A. R., \& Shalahuddin, 2014) menyatakan, "Use case atau diagram use case merupakan pemodelan untuk kelakuan (behavior) sistem informasi yang akan dibuat". Use Case Diagram adalah gambaran diagram aktivitas yang dilakukan oleh suatu sistem dari sudut pandang pengamatan luar, dimana hal itu menjadi persoalan apa yang dilakukan bukan bagaimana melakukannya.

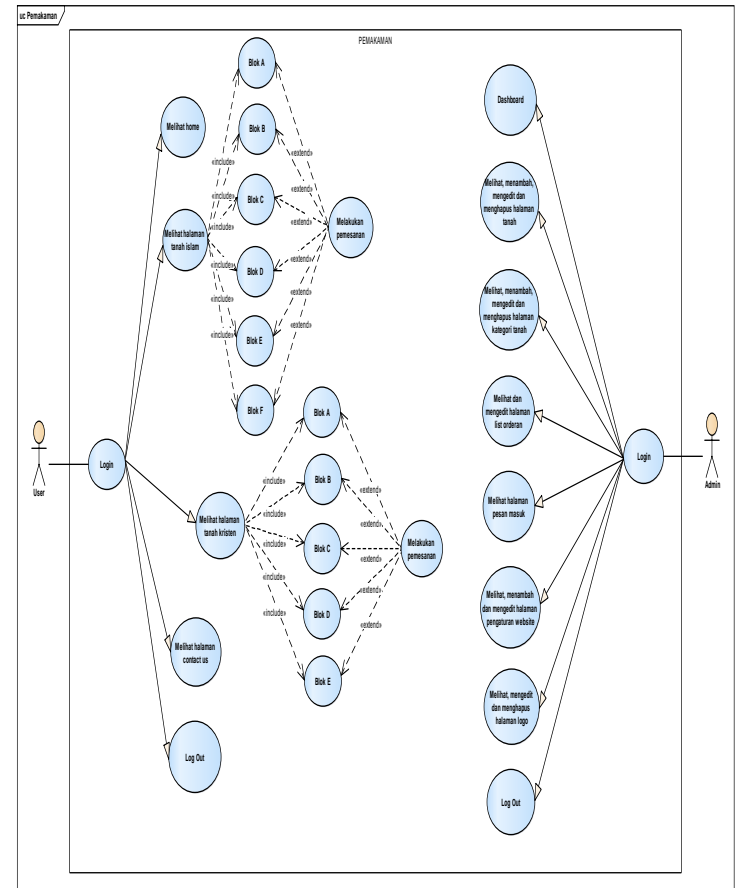

Sumber : penelitian 2020

\section{Gambar 2. Use Case Diagram}

\section{c. Logical Record Structured (LRS)}

Menurut (Taufiq dan Ermawati, 2017) "Sebelum tabel dibentuk dari field atau atribut entitas secara fisik atau level internal, maka harus dibuatkan suatu bentuk relational model yang dibuat secara logic atau level external dan konsep, dari pernyataan tersebut dibutuhkan yang disebut dengan Logical Record Structure (LRS)".

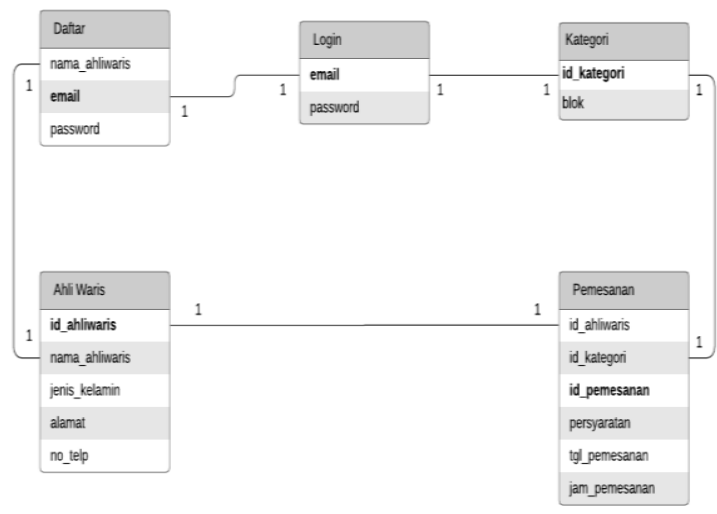

Sumber : penelitian 2020

\section{Gambar 3. Logical Record Structured (LRS)}

\section{d. Entity Relationship Diagram (ERD)}

Menurut (Fathansyah, 2018) Entity Relationship Diagram (ERD) adalah komponen-komponen himpunan entitas dan himpunan relasi yang masingmasing dilengkapi dengan atribut-atribut yang mempresentasikan seluruh fakta di dunia nyata". 


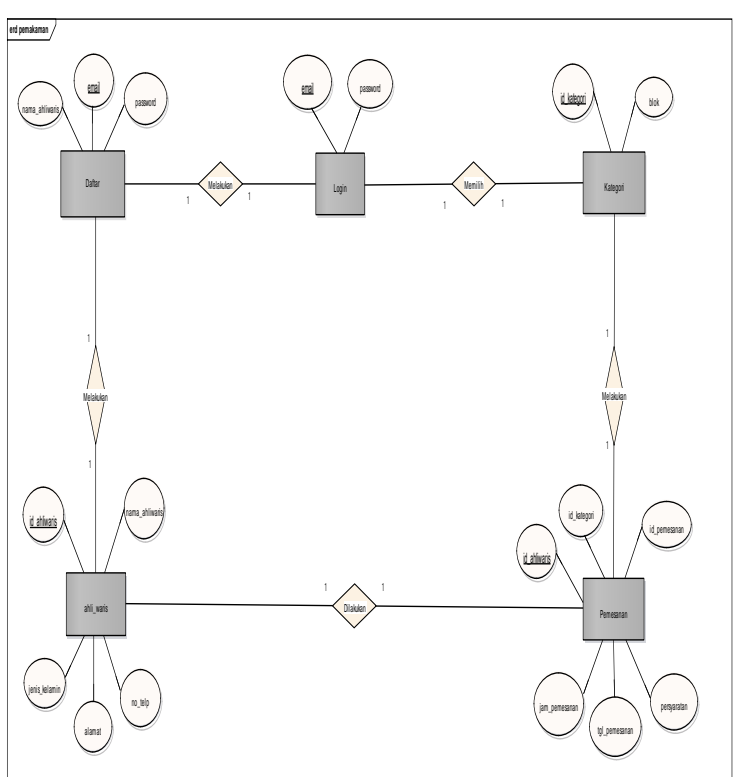

Sumber : penelitian 2020

Gambar 4. Entity Relationship Diagram (ERD)

e. Implementasi Rancangan Antar Muka rancangan antar muka daftar izin penggunaan tanah makam digunakan oleh ahli waris saat ingin mendaftarkan penggunaan sewa tanah makam. Ini dapat dilakukan setelah ahli waris melakukan login terlebih dahulu.

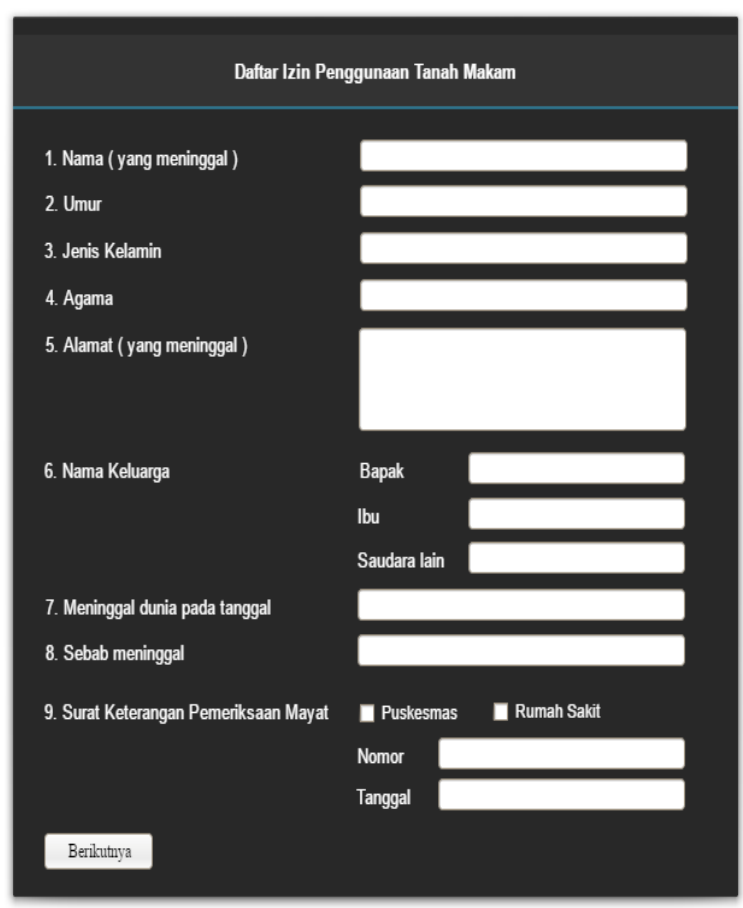

Sumber : penelitian 2020

\section{Gambar 4. Daftar Izin Penggunaan Tanah Makam}

\section{KESIMPULAN}

Sistem Informasi Penyewaan Tanah Makam pada TPU Perwira dalam penelitian ini dapat mendata ketersediaan lokasi yang ada untuk memakamkannya, memudahkan masyarakat dalam proses pemesanan lahan makam, sehingga membuat proses pemesanan lahan makam menjadi lebih efesien. Membantu masyarakat untuk memperoleh informasi yang lebih jelas mengenai kepemilikkan makam. Perlu diadakan pelatihan kepada pengguna dan mengantisipasi kesalahan yang mungkin timbul pada program. Perangkat yang digunakan untuk menjalankan program hendaknya sesuai dengan spesifikasi yang dibutuhkan agar program dapat berjalan dengan baik. Penelitian berikutnya sebaiknya dilanjutkan pada tahapan selanjutnya yaitu perbaikan sistem keamanan data agar lebih baik lagi dan penambahan fungsi dari program agar sesuai kebutuhan.

\section{REFERENSI}

Ardhana, Y. K. (2012). PHP: Menyelesaikan Website 30 Juta. Jasakom.

Debiyanti, D., Sutrisna, S., Budrio, B., Kamal, A. K., \& Yulianti, Y. (2020). Pengujian Black Box pada Perangkat Lunak Sistem Penilaian Mahasiswa Menggunakan Teknik Boundary Value Analysis. Jurnal Informatika Universitas Pamulang, 5(2), 162. https://doi.org/10.32493/informatika.v5i2.544 6

Fathansyah. (2018). Basis Data Revisi Ketiga. Pengertian Sistem Menurut Para Ahli.

Haryadi, A. F., \& Melian, L. (n.d.). Rancang Bangun Aplikasi Pemakaman Berbasis Web Build Web-Based Funeral Applications. 112. https://repository.unikom.ac.id/54679/1/vii-1adi-firman-haryadi-rancang-bangun-aplikasipemakaman-berbasis-web.pdf

Hirmawan, A., P, M., \& Azizah, D. (2016).

$\begin{array}{lcr}\text { ANALISIS } & \text { SISTEM } & \text { AKUNTANSI } \\ \text { PENGGAJIAN } & \text { DAN } & \text { PENGUPAHAN } \\ \text { KARYAWAN } & \text { DALAM } & \text { UPAYA }\end{array}$

MENDUKUNG PENGENDALIAN INTERN (Studi pada PT.Wonojati Wijoyo Kediri). Jurnal Administrasi Bisnis S1 Universitas Brawijaya, 34(1), 189-196. http://administrasibisnis.studentjournal.ub.ac.i d/index.php/jab/article/view/1333

Krispriana, A., Kumaladewi, N., \& Rahajeng, E. (2018). Sistem Informasi Computer Assisted Test (Cat) Kementerian Agama Republik Indonesia. Studia Informatika: Jurnal Sistem Informasi, $\quad$ 9(2), 203-211. http://journal.uinjkt.ac.id/index.php/sisteminfo rmasi/article/view/7649

Morris, J. E. (1942). Waterfalls. Notes and Queries, 
182(23),

321.

https://doi.org/10.1093/nq/182.23.321-a

Padang, Y. S., Sumaryanti, L., \& Kolyaan, Y. (2018). Sistem Informasi Tempat Pemakaman Umum Tanah Miring Kabupaten Merauke Berbasis Web. Musamus Journal Of Research Information and Communication Technology, l(1), 18-29. https://doi.org/10.35724/mjrict.v1i1.1007

Pratama, I., \& Eka, P. A. (2014). Sistem Informasi dan Implementasinya. Bandung Inform.

Rusman. (2013). Metode-Metode Pembelajaran: Mengembangkan Profesionalisme Guru. PT. Raja Grafindo Persada.

Sukamto, A. R., \& Shalahuddin, M. (2014). Rekayasa Perangkat Lunak Terstruktur dan Berorientasi Objek. Infromatika.

Sukrianto, D., \& Agustina, S. (2018). Pemanfaatan Sms Gateway Pada Sistem Informasi Absensi Siswa Di Sman 12 Pekanbaru Berbasis Web. Jurnal Intra Tech, 2(2), 78-90. http://www.journal.amikmahaputra.ac.id/index .php/JIT/article/view/31

Taufiq dan Ermawati. (2017). Perancangan Sistem Informasi Pemesanan Pentas Seni Berbasis Web Pada Sanggar Seni Getar Pakuan Bogor. IJSE - Indonesian Journal on Software Engineering, 3(2), 1-7. http://ejournal.bsi.ac.id/ejurnal/index.php/ijse/ article/view/2812/1836

Trianto, B., \& Setiawan, R. (2020). RANCANG BANGUN SISTEM INFORMASI PENGELOLAAN MAKAM BERBASIS WEB PADA PEMAKAMAN WAKAF BUNGUR KEBAYORAN LAMA. Jurnal Sistem Informasi Dan Sains Teknologi, 2. http://trilogi.ac.id/journal/ks/index.php/SISTE K/article/view/673/363 